\title{
SIMULATION OF PARTICLE MOVEMENT IN CRUSHING CHAMBER OF ROTARY GRAIN CRUSHER
}

\author{
Peter Savinyh ${ }^{1}$, Alexey Aleshkin ${ }^{2}$,Vladimir Nechaev ${ }^{3}$, Semjons Ivanovs ${ }^{4}$ \\ ${ }^{1}$ North-East Agricultural Research Institute, Russia; ${ }^{2}$ VyatkaStateUniversity, Russia; \\ ${ }^{3}$ Nizhegorod State Engineering Economic University, Russia; ${ }^{4}$ Latvia University of Agriculture \\ semjons@apollo.lv
}

\begin{abstract}
A design and technological scheme of the grain crusher of shock-reflective action has been developed. As a result of the conducted research, dependences have been established describing the relative motion of a particle along the rotor blade at particular values of the angular velocity of the rotor, the angular coefficient of the plane, the coefficient of friction, and time. Analysis of the impact of individual indicators was carried out with the help of a developed program, tested under laboratory conditions. The research allows developing an efficient grain crusher at the design stage, to determine such adjusting parameters by which it is possible to obtain a finished product with a minimum energy intensity and maximum productivity.
\end{abstract}

Keywords: grain, crusher, rotor blades, particle movement.

\section{Introduction}

Grain is a valuable source of feed for farm animals. However, in order to increase the digestibility of the nutritional elements and their quality, as well as to obtain various feed mixtures, appropriate processing and preparation for feeding are required, including crushing [1].

Efficient methods of preparing grain for feeding are crushing and grinding. Grinding of grain is used more for the production of food flour for baking bread and confectionery products. Crushing of grain is widely used for the preparation of feed for animals on the farms and in the mixed feed industry. Due to their high efficiency and the wide range of grinding, rotary crushers are widely used [2].

In the exploration process of the operation of rotary grain crushers, the main regularities determining the efficiency, the degree of crushing, the energy consumption, etc. were revealed [3-6]. However, with the development of the feeding technologies, new requirements are imposed on the operation of the crushers, and constant improvement of their structures is required.

During the research $[7 ; 8]$ it was revealed that one of the main problems of rotary crushers is the heterogeneity of the crushed grain by its fractional composition and the high energy intensity of the process. First of all, this is due to untimely removal of the finished product from the crushing chamber.

Therefore, the development of these machines with justified optimal design parameters is an important and urgent task. Establishment of theoretical regularities of the crushing process allows us to determine the optimal ranges of parameters and, already at the design stage, to make appropriate corrections in the design.

The aim of this work was a mathematical description of the interaction of grain with the rotor blades, and the development of a model for the movement of a particle in the crushing chamber of the rotary grain crusher.

\section{Materials and method}

The grain crusher $[9 ; 10]$, used in the experimental studies, consists of a frame 1 , a demountable body 13 including a cylindrical, horizontally disposed drum, a removable plate 11 and a lid 8 , forming a crushing chamber, a hopper 5 and discharge openings 10. In the crushing chamber, there is mounted a rotor with blades 12, arranged at an angle with respect to their axes. This feature of the rotor design improves the pressure characteristic of the working space of the crusher. A consequence of this is the high effect of impact of the blades upon the grain. To ensure timely withdrawal of the finished product from the crushing chamber, hence to improve the efficiency of the crushing process, sieves 6,7 are installed along the periphery and at the end of the rotor. The rotor 12 is rotated by the electric motor 2 through the belt transmission 4 .

The crusher works in the following way. After the electric motor 2 is turned on, the material enters through the loading opening 10 into the crushing chamber where it falls under the tangential impacts of the rotating blades of the rotor 12. Crushing of grain occurs as a result of repeated 
interaction of the blades 12 and sieves 6,7 . The crushed grain is sifted through the holes of the sieves 6, 7 and through the discharge nozzle 9 enters the hopper or another receptacle. The coarse fraction continues movement inside the crushing chamber, being crushed to the required dimensions. Due to the design features of the crusher, its reliability is raised, the crushing efficiency of the grain material is increased.

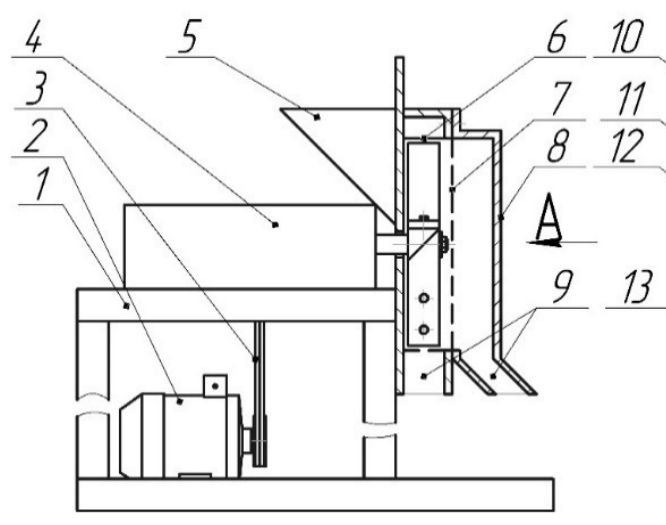

a

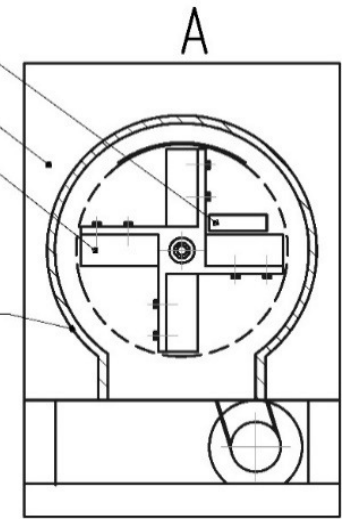

$\mathrm{b}$

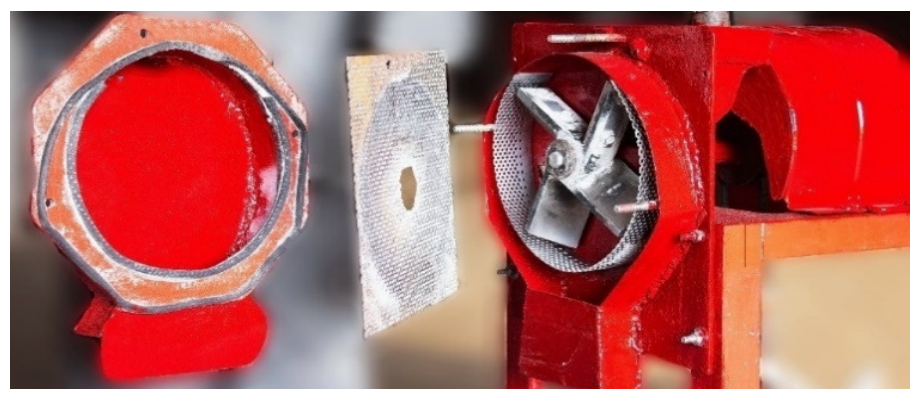

c

Fig. 1. Structural arrangement of the experimental grain crusher: a) - general view; b) - side view (the cover and the end sieve removed); c) - photo scheme: 1 - frame; 2 - electric motor; 3 - belt drive; 4 - casing; 5 - loading hopper; 6 - peripheral sieve; 7 - end sieve; 8 - housing cover; 9 - discharge nozzles; 10 - loading opening; 11 - plate; 12 - rotor with blades; 13 - housing

Simulation of the grain movement in the crushing chamber of a rotary grain crusher was carried out. On the basis of the general laws of the mechanics of relative motion, we obtained equations that allow one to predict the position of the particle in the crushing chamber with particular parameters, to determine the kinematic characteristics as the derivatives of the time coordinates, and also to represent its movement in a graphical form, depending on the rotor rotation angle. From a technical point of view, this makes it possible to trace how the grain behaves while being in the crushing chamber. It comes onto the blades, slides along them and, under the influence of centrifugal force, descends on the sieves, or, at the first impact against the blade, flies back onto the sieve. In our case, the circumferential velocity of the rotor is in the region of $70 \mathrm{~m} \cdot \mathrm{s}^{-1}$, allowing intense destruction of the grain against the blade or the sieve.

In the mathematical description of the grain movement in the crushing chamber, we made the following assumptions: the particle is on the blade and it moves singly, it has the shape of a ball (Fig. 2 ), and the air flow is constant by its magnitude and speed.

The equation of the plane of movement in movable axes is parallel to the axis $x$ :

$$
z=k y-b,
$$

where $k=\operatorname{tg} \alpha-$ angular coefficient of the plane.

$b$ - displacement of the section of the working plane of the blade in the plane of axes $(y$,

$z$ ) with respect to the origin of coordinates $(y, z)$. 
The working plane of the blade is parallel to the $x$ axis, therefore the addend $b$ determines the deflection of any straight line, parallel to the axis $x$ and lying in the plane of the blade, from the radial direction in the direction opposite to the direction of rotation of the disk.

We suppose that $\vec{w}_{r}=\frac{d^{2} \vec{r}}{d t^{2}}$ is relative acceleration of a particle

$$
\vec{w}_{r}=m \vec{g}+\vec{N}+\vec{F}_{T}+\vec{F}_{e}+\vec{F}_{C},
$$

where $m$ - mass of the particle;

$\vec{w}_{r}$ - relative acceleration;

$m \vec{g}$ - force of gravity: $m \vec{g}=\vec{i}_{1} \cdot 0+\vec{j}_{1} \cdot 0+\vec{k}_{1} \cdot(-m g)$;

$\vec{N}$ - normal reaction of the plane of motion (of the blade);

$\vec{F}_{T}$ - force of friction against its surface;

$\vec{F}_{e}$ - transportation force of inertia;

$\vec{F}_{C}-$ Coriolis force of inertia.

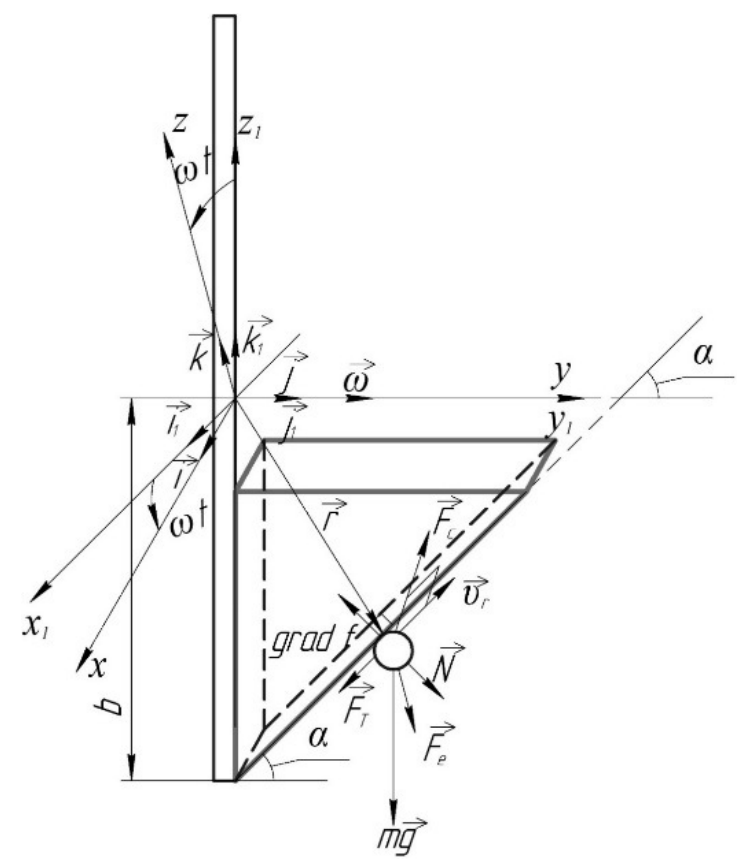

Fig. 2. Movement of grain along the blade in the crushing chamber:

$$
z_{1}, x_{1}, y_{1} \text { are fixed axes; } z, x, y-\text { moving axes }
$$

Accordingly, in a rotating frame of reference:

$$
\left\{\begin{array}{l}
m g_{x}=m g \sin (\omega t) \\
m g_{y}=0 \\
m g_{z}=(-m g) \cos (\omega t)
\end{array},\right.
$$

where $\vec{N}$-normal reaction of the plane of motion:

$$
\left(\vec{N}=\lambda \operatorname{grad} f, \operatorname{grad} f=\frac{d f}{d x} \cdot \vec{i}+\frac{d f}{d y} \cdot \vec{j}+\frac{d f}{d z} \cdot \vec{k}\right)
$$




$$
\left\{\begin{array}{l}
N_{x}=\lambda \frac{d f}{d x} \\
N_{y}=\lambda \frac{d f}{d y} \\
N_{z}=\lambda \frac{d f}{d z}
\end{array}\right.
$$

where $\lambda$-indefinite Lagrange multiplier.

The equation of the constraint surface

$$
\begin{gathered}
f=z-k y+b=0, \\
\left\{\begin{array}{l}
\frac{d f}{d x}=0 \\
\frac{d f}{d y}=-k \Rightarrow\left\{\begin{array}{l}
N_{x}=0 \\
N_{y}=-k \lambda, \\
N_{z}=\lambda
\end{array}\right. \\
\frac{d f}{d z}=1 \\
|N|=\sqrt{k^{2} \lambda^{2}+\lambda^{2}}=|\lambda| \cdot \sqrt{k^{2}+1}
\end{array}\right.
\end{gathered}
$$

$\vec{F}_{T}$ - force of friction against the plane of motion with the coefficient of friction $f_{T}$

$$
\begin{gathered}
\vec{F}_{T}=-|N| f_{T} \frac{\vec{v}_{r}}{\left|\vec{v}_{r}\right|}, \\
\left\{\begin{array}{l}
v_{r x}=\dot{x} \\
v_{r y}=\dot{y}, \\
v_{r z}=\dot{z}
\end{array}\right. \\
\left|\vec{v}_{r}\right|=\sqrt{\dot{x}^{2}+\dot{y}^{2}+\dot{z}^{2}}, \\
F_{T x}=-|\lambda| \sqrt{k^{2}+1} \cdot f_{T} \frac{\dot{x}}{\sqrt{\dot{x}^{2}+\dot{y}^{2}+\dot{z}^{2}}} \\
F_{T y}=-|\lambda| \sqrt{k^{2}+1} \cdot f_{T} \frac{\dot{y}}{\sqrt{\dot{x}^{2}+\dot{y}^{2}+\dot{z}^{2}}}, \\
F_{T z}=-|\lambda| \sqrt{k^{2}+1} \cdot f_{T} \frac{\dot{z}}{\sqrt{\dot{x}^{2}+\dot{y}^{2}+\dot{z}^{2}}}
\end{gathered}
$$

where $\vec{F}_{e}-$ Centrifugal force of inertia

$$
\begin{aligned}
\vec{F}_{e} & =-m \vec{\omega} \times(\vec{\omega} \times \vec{r}), \\
\vec{\omega} & =0 \vec{i}+\omega \vec{j}+0 \vec{k}, \\
\vec{r} & =x \vec{i}+y \vec{j}+z \vec{k},
\end{aligned}
$$




$$
\begin{aligned}
& \vec{\omega} \times \vec{r}=\left|\begin{array}{ccc}
\vec{i} & \vec{j} & \vec{k} \\
0 & \omega & 0 \\
x & y & z
\end{array}\right|=\vec{i} \cdot \omega z+\vec{j} \cdot 0+\vec{k}(-\omega x), \\
& \vec{\omega} \times(\vec{\omega} \times \vec{r})=\left|\begin{array}{ccc}
\vec{i} & \vec{j} & \vec{k} \\
0 & \omega & 0 \\
\omega z & 0 & (-\omega x)
\end{array}\right|=-\vec{i} \cdot \omega^{2} x++\vec{j} \cdot 0+\vec{k}\left(-\omega^{2} z\right), \\
& F_{e x}=+m \omega^{2} x \\
& F_{e y}=0 \\
& F_{e z}=+m \omega^{2} z
\end{aligned}
$$

$\vec{F}_{C}-$ Coriolis inertia force

$$
\begin{gathered}
\vec{F}_{C}=-2 m \vec{\omega} \times \vec{v}_{r}, \\
\vec{\omega} \times \vec{v}_{r}=\left|\begin{array}{ccc}
\vec{i} & \vec{j} & \vec{k} \\
0 & \omega & 0 \\
\dot{x} & \dot{y} & \dot{z}
\end{array}\right|=\vec{i}(\omega \dot{z})+\vec{j} \cdot 0+\vec{k}(-\omega \dot{x}), \\
\left\{\begin{array}{l}
F_{C x}=-2 m \omega \dot{z} \\
F_{C y}=0 \\
F_{C z}=-2 m \omega \dot{x}
\end{array}\right.
\end{gathered}
$$

\section{Results and discussion}

Substituting the projections of all forces into the original differential equation in the projection on the axis $(x y z)$, we obtain:

$$
\left\{\begin{array}{l}
m \ddot{x}=m g \sin (\omega t)-|\lambda| \sqrt{k^{2}+1} \cdot f_{T} \frac{\dot{x}}{\sqrt{\dot{x}^{2}+\dot{y}^{2}+\dot{z}^{2}}}+m \omega^{2} x-2 m \omega \dot{z} \\
m \ddot{y}=-k \lambda-|\lambda| \sqrt{k^{2}+1} \cdot f_{T} \frac{\dot{y}}{\sqrt{\dot{x}^{2}+\dot{y}^{2}+\dot{z}^{2}}} \\
m \ddot{z}=-m g \cos (\omega t)+\lambda-|\lambda| \sqrt{k^{2}+1} \cdot f_{T} \frac{\dot{z}}{\sqrt{\dot{x}^{2}+\dot{y}^{2}+\dot{z}^{2}}}+m \omega^{2} z-2 m \omega \dot{z}
\end{array}\right.
$$

Supplementing these equations with initial conditions, for example, the particle is on half the radius of the disk along the axis $x$ :

$$
x(0)=R / 2 ; \dot{x}(0)=0 ; y(0)=0 ; \dot{y}(0)=0 ; z-b=0 ; \dot{z}(0)=0 ; \lambda(0)=\lambda_{0}
$$

We obtain conditions for the solution of the Cauchy problem. The solution of the differential equations must be carried out numerically. From the constraint equation we obtain:

$$
\left\{\begin{array}{l}
z=k y-b \\
\dot{z}=k \dot{y} \\
\ddot{z}=k \ddot{y}
\end{array}\right.
$$

From the second and third equations, we will express the factor $\lambda$ as a function of time for $m=1$ : 


$$
\begin{gathered}
\ddot{y}=-k \lambda+F_{T y}, \\
\ddot{z}=k \ddot{y}=-k^{2} \lambda+k F_{T y}, \\
-k^{2} \lambda+k F_{T y}-\lambda=-g \cos \omega t+F_{T z}+\omega^{2} z+2 \omega \dot{x} \\
-\lambda\left(1+k^{2}\right)=-k F_{T y}+F_{T z}-g \cos \omega t+\omega^{2} z+2 \omega \dot{x}, \\
\lambda=\frac{1}{\left(1+k^{2}\right)}\left(-F_{T z}+k F_{T y}-g \cos \omega t-\omega^{2} z-2 \omega \dot{x}\right), \\
-F_{T z}+k F_{T y}=-\frac{|\lambda| \sqrt{k^{2}+1} \cdot f_{T p}}{\sqrt{\dot{x}^{2}+\dot{y}^{2}+\dot{z}^{2}}}(-\dot{z}+k \dot{y})=0, \\
\lambda=\frac{1}{\left(1+k^{2}\right)}\left(g \cos \omega t-\omega^{2} z-2 \omega \dot{x}\right),
\end{gathered}
$$

since $\quad-\dot{z}+k \dot{y}=0$.

Note that $\vec{N}=\lambda \operatorname{grad} f$ at $\lambda<0$ with the normal reaction of the blade $N>0$.

That is, for the particle to move along the blade, the value of $\lambda$ must be less than zero.

From the system of the differentiated equations (21) we take the first two equations, and the third one we replace by the equation (29), which closes the system.

We define the coordinate $z(t)$ by the constraint equation (1). Thus, for a numerical solution we have a system of equations:

$$
\left\{\begin{array}{l}
\ddot{x}=g \sin \omega t-|\lambda| \sqrt{k^{2}+1} f_{T} \frac{\dot{x}}{\sqrt{\dot{x}^{2}+\dot{y}^{2}+\dot{z}^{2}}}+\omega^{2} x-2 \omega \dot{z} \\
\ddot{y}=-k \lambda-|\lambda| \sqrt{k^{2}+1} f_{T} \frac{\dot{y}}{\sqrt{\dot{x}^{2}+\dot{y}^{2}+\dot{z}^{2}}} \\
\lambda=\frac{1}{\left(1+k^{2}\right)}\left(g \cos \omega t-\omega^{2}(k y-b)-2 \omega \dot{x}\right)
\end{array}\right.
$$

with the initial conditions for the system (21).

The results of the solution are obtained numerically, with the angular velocity of the rotor, the angular coefficient of the plane, the coefficient of friction, some real number and time being given. Calculation of the parameters of the particle movement along the blade in the crushing chamber was carried out on a PC using the "Accelerated acceleration method" program, written in the language "Visual C \#". The program for the calculation of the parameters of a particle movement is designed in such a way that it makes it possible to conduct an analysis of any indicator that influences its movement and enters into these equations.

For comparison, the number $b= \pm 0.05 \mathrm{~m}$, the previously fixed optimal angular coefficient of the plane (angle of inclination of the plane) $k=1\left(\alpha=45^{\circ}\right)$ [10], at the angular velocity $\omega=300 \mathrm{~s}^{-1}$, $\lambda_{0}=-100$ and the coefficient of friction $f=0.1$. The investigations were performed with a time interval $\Delta t=0.0001 \mathrm{~s}$. After substituting the initial conditions into the program, we obtain the real time values showing the position of the particle, its velocity, acceleration, and the factor $\lambda$. In our case, the change in the Lagrange multiplier, which causes the greatest interest, is represented in a graphical form (Fig. 3). At $b=0.05$, the factor $\lambda$ in the first step instantly changes the sign: $\lambda_{0}=-100$ (this value is not visible, since the step is very small), and then assumed the value $\lambda=2254$. In essence, this indicates that the particle, when struck against the blade immediately flies back to the sieve. The lines shown in the graph at $b=0.05 \mathrm{~m}$ and the initial velocity $\dot{x}=0 \mathrm{~m} \cdot \mathrm{s}^{-1}$ have only a purely theoretical meaning (in 
which the particle is pressed and slides along a conditional (non-existent) surface), and we do not consider it.

As it can be seen from Fig. 3, at $b=0.05 \mathrm{~m}$, in a short time interval, the curve $\lambda$ (Figure 3) intersects the zero value of the axis, that is, the particle is pressed and slides along a conditional (nonexistent) surface. We do not consider this movement.

At $b=-0.05 \mathrm{~m}$ and the value $\lambda<0$ (Fig. 3), under the action of the Coriolis force, the particle is pressed to the blade and slips until the bulk velocity of its movement is acquired. This movement causes wear and heating of the blades, especially when $k<1$. The cases considered show the movement of a particle when there is no velocity along the axis $x$ or it is very small.

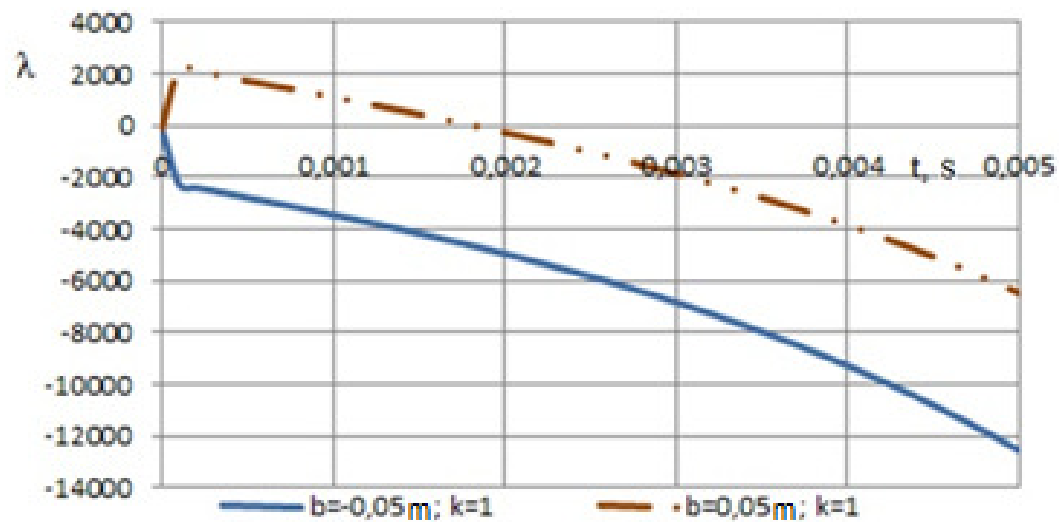

Fig. 3. Graph of the change in the indeterminate Lagrange multiplier depending on time at the initial velocity $\dot{x}=0 \mathrm{~m} \cdot \mathrm{s}^{-1}$

At velocities $\dot{x} \geq 8 \mathrm{~m} \cdot \mathrm{s}^{-1}$ the particle moves with a slip in both cases $b= \pm 0.05 \mathrm{~m}$ (Fig. 4). But, proceeding from the system of equations (11) and Figure 5 with $b=0.05 \mathrm{~m}$, the wear will be much less.

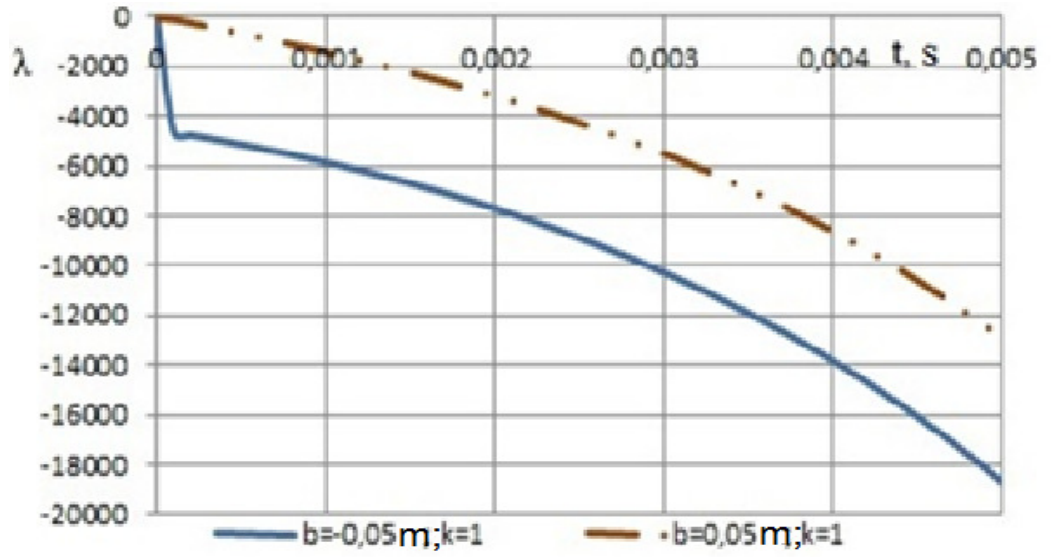

Fig. 4. Graph of the change in the indeterminate Lagrange multiplier depending on time at the initial velocity $\dot{x}=8 \mathrm{~m} \cdot \mathrm{s}^{-1}$

At a positive distance $b$ (values $k$ in equation (1) being investigated), the particle does not slip along the blade, and after the collision it bounces off from it, that is, the shock effect is only due to interaction with the rotor. At a negative value of $b$, after striking the blade, the particle slides over its surface and acquires a travelling speed of the blade and interacts with the fixed boundaries of the grinding chamber, at a higher absolute speed than in the first case. That is, it is subjected to a more intense impact, but, to reduce the sieve wear, it is advisable to destroy the particles when they strike the blade (at $b>0$ ).

Fig. 5 shows the blades after crushing $50 \mathrm{~kg}$ of barley. They have marked chips on them in the form of white dots. Obviously, the points are the places of impact without slip, which confirms the conclusions drawn. 


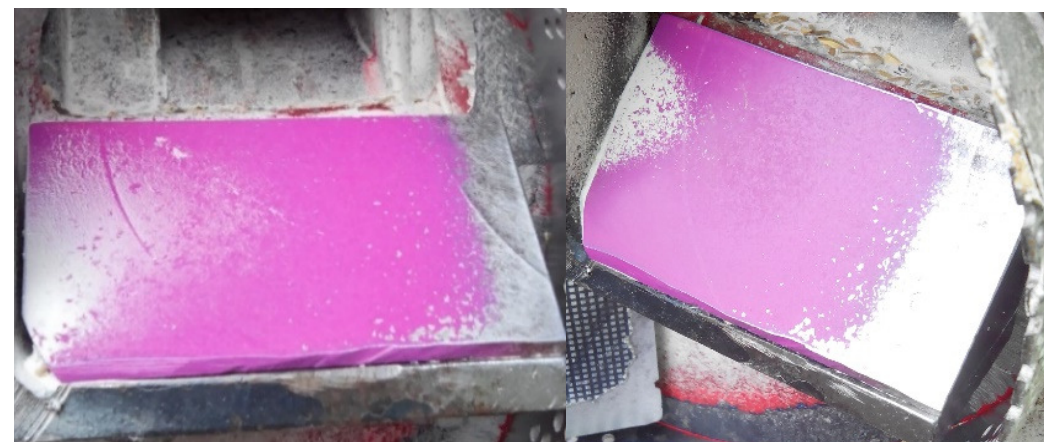

Fig. 5. General view of the rotor blades after the tests at $k=1, b=0.05 \mathrm{~m}$

\section{Conclusions}

1. As a result of the conducted research, there are established dependences describing the relative movement of a particle along the rotor blade at particular values of the angular velocity, the angular coefficient of the plane, the coefficient of friction and time.

2. It has been established that by setting a positive or negative parameter $b$ it is possible to achieve the necessary effect of grain particle destruction. When $b<0$ (that is, when the working plane of the blade is above the axis $x$ when $y=0$ ), at first the particle slides along the blade and then descends at a certain speed, and further destruction of it occurs by impacting against the sieve (lattice). If $b>0$ (that is the blade is set below the axis $x$ at $y=0$ ), then crushing takes place by striking the particle against the blade itself, and it bounces off the blade without a relative slip. This option is preferable if it is necessary to ensure the destruction of the grain upon impact against the blade, rather than against the sieve for the purpose of less wear of the latter.

\section{References}

1. Sysuev V., Ivanovs S., Savinyh P., Kazakov V. Movement and transformation of grain in twostage crusher Engineering for Rural Development, Proceedings, Volume 14, 2015. pp. 22-27.

2. Сысуев В., Алёшкин А., Савиных П. Кормоприготовительные машины. (Forage Preparation Machines), т. 1., Kirov, 2009. 639 p. (In Russian).

3. Vaculik P., Maloun J., Chladek L., Poikryl M. Disintegration process in disc crushers. Research in Agricultural Engineering. Volume 59, Issue 3, 2013, pp. 98-104.

4. Sysuev V., Savinyh P., Aleshkin A., Ivanovs S. Simulation of elastic deformation propagation of grain under impact crushing in crusher. Engineering for Rural Development, Proceedings, Volume 15, 2016, pp.1065-1071.

5. Савиных П., Булатов С., Нечаев В. Исследование рабочего процесса молотковой дробилки зерна с ротором-вентилятором (Investigation of the working process of a hammer mill with a rotor-fan).АграрнаянаукаЕвро-Северо-Востока. 2013. o 1, pp. 54-59. (In Russian).

6. Булатов С.Ю., Нечаев В.Н., Савиных П.А. Разработка дробилки зерна для крестьянских хозяйств (Development of a grain crusher for peasant farms), 2014. 156 p. (In Russian).

7. Savinyh P., Nechaev V., Nechaeva M., Ivanovs S. Motion of grain particle along blade of rotor fan of hammer crusher. Engineering for rural development. Jelgava, 2016. Vol. 15. pp. 1072-1079.

8. Савиных П.А., Нечаев В.Н., Нечаева М.Л. Совершенствование комбикормового оборудования (Improvement of the mixed fodder equipment). Вестник НГИЭИ. 2016. Vol 4(59). pp. 111-118.(In Russian).

9. Savinyh P., Saitov E., Turubanov N. Grain crusher. Patent RU 2558248, 2015, 6 p.

10. Savinyh P., Bulatov S., Nechaev V. Badania eksperymentalne rozdrabniaczna bijakowego do ziarna określenie wpływu konstrukcyjnych cech na charakterystykę technologiczną.Problems of intensification of animal production including environment protection and alternative energy production as well as biogas. Materialy na konferencje Warszawa: ITP, 2016. Vol. XXII. pp. 195-202. 